\title{
Review on Tea (Camellia sinensis) Research Achievements, Challenges and Future Prospective Including Ethiopian Status
}

\author{
Mohammedsani Zakir \\ Ethiopian Institute of Agricultural Research; Jimma Agricultural Research Center, Jimma Ethiopia
}

Corresponding Author: Mohammedsani Zakir, Ethiopian Institute of Agricultural Research; Jimma Agricultural Research Center, Jimma Ethiopia

\begin{abstract}
Tea [Camellia sinensis (L.) O. Kuntze] is one of the most popular and lowest cost beverages in the world, and consumed by a wide range of age groups in all levels of society with more than three billion cups daily worldwide. Tea breeding strategy such as source of gene pool, selection of elite mother bushes and assessment of made tea quality reviewed. Tea research achievement in breeding, eco-physiology, and biochemical; production of tea in China, India, Kenya, Sri Lanka and Vietnam was considered. The challenges like mini-manufacture, cost assessment, climate change, time consuming protocols, pest and diseases; cost of assessment including constraints of Ethiopian tea industry was reviewed well. Future prospects of tea research main research emphases of tea genetics and breeding in the future, deepening the functional genome research to reveal special gene resources, enhancing the basic genetic research for breeding, conducting distant hybridization to enhance germplasm innovation, improving gene transformation technique to use exogenous genes, Perfecting molecular marker assisted technique to effectively conduct early-stage appraisal and similar procedures should be integrated in the future tea research in order to cope up with the currently existing environmental phenomena.
\end{abstract}

Keywords: Tea, Research, achievement, Challenges, Prospective, Ethiopia

\section{INTRODUCTION}

Tea [Camellia sinensis (L) O. Kuntze], is one of the most popular and lowest cost beverages in the world, and consumed by a wide range of age groups in all levels of society with more than three billion cups daily worldwide (Hick, 2009). Majority of the tea producing countries are located in the continent of Asia where China, India, Sri Lanka are the major producers. African tea growing countries are located mostly around the tropical regions where Kenya, Malawi, Rwanda, Tanzania, Uganda are major producers. Apart from these regions, some quantities of tea are also being produced in South America (Argentina, Brazil and others), the Near East (Iran and Turkey) and the CIS (Russia and Georgia). Amongst tea producing countries, the principal producers are China, India, Sri Lanka, Kenya and Indonesia. In terms of area under tea plantation, on an average during the last two decade (1991 - 2010), China lead (45\%) the world followed by India (21\%), Sri Lanka (7\%), Kenya (5\%), Vietnam (3\%) (Basu et al, 2012).

The Tea Research Institute (TRI) is the only comprehensive institute dedicated to tea research at the national level in China. The institute holds the second largest tea preservation resource in the world and currently conserves 3,013 different tea germplasm resources, encompassing the most genetic diversity of any tea resource in the world. In total, researchers at TRI have contributed 225 scientific and technological advances to the field 106 of these achievements have been recognized with awards, including eight national and 39 ministerial prizes. The institute has bred eight nationally certified tea varieties, has been granted 45 patents, and has established one international standard, 25 national standards, and 51 industrial standards for tea production (Sean, 2013). The first tea planted in Africa was in 1850 in the Durban Botanical Garden on the eastern shore of South Africa near the port of Durban which was China type. In order to improve yield and quality of the crop in Southern Africa the Tea Research Foundation of Central Africa (TRFCA) was established in Malawi in 1933, initially as a tea research station under the department of agriculture before gaining autonomy in 1966 . The TRFCA has an active plant breeding and selection program aimed at solving tea production problems such as drought, extreme temperatures, pests and diseases, low yield and low quality, under local 
Review on Tea (Camellia Sinensis) Research Achievements, Challenges and Future Prospective Including Ethiopian Status

growing conditions in order to increase productivity and maximize total value and income from the crop (Apostolides et al., 2006).

\section{BODY OF THE TEXT}

\subsection{The Achievements of Tea Genetic Improvement and Breeding}

\subsubsection{Breeding of the Tea Plant (Camellia sinensis) in China}

China has abundant tea genetic resources capable of providing diverse parent materials for tea breeding. Different methods, which included ex-situ, in-situ and in vitro, were employed to prevent the loss of tea germplasm and ensure the preservation of genetic diversity. The tea germplasms have been evaluated and appraised based on morphology, physiology, agronomy, cytology and molecular biology, through which the elite and unique tea accessions were screened and further utilized in tea breeding. An efficient tea breeding system, in which controlled hybridization and individual selection are the main breeding approaches, combined with molecular marker assisted selection and micropropagation techniques, has now been established and gradually developed in China. Up to date, a total of 123 cultivars have been registered as national tea cultivars. More than 150 cultivars have been accredited for release in given provinces and 4 clones have been covered by Plant Varieties Protection (PVP) in China (Ming and Liang, 2012). By the end of 2005, China had 97 national registered cultivars, among them 17 are jats, 80 are clones, 30 are landraces and 67 are improved clones (Table 1). They are bred by 23 different institutions including the national and local tea research institutes, agricultural universities, local agricultural departments, tea experimental stations, etc. There were also about 130 provincial registered cultivars, among them 16 are jats, 114 are clones, 29 are landraces and 101 are improved clones, respectively (Yu, 2005; Liang et al., 2007).

Table1: Brief introduction to the Chinese national registered cultivars

\begin{tabular}{|c|c|c|c|c|c|c|c|}
\hline no & Cultivars & $\begin{array}{l}\text { Register } \\
\text { ed year }\end{array}$ & $\begin{array}{l}\text { Breeding } \\
\text { method }\end{array}$ & no. & Cultivars & $\begin{array}{l}\text { Register } \\
\text { ed year }\end{array}$ & $\begin{array}{c}\text { Breeding } \\
\text { method }\end{array}$ \\
\hline 1 & Fuding Dabaicha & 1985 & Landrace & 50 & Yunkang 10 & 1987 & Field clone \\
\hline 2 & Fuding Dahaocha & 1985 & Landrace & 51 & Yunkang 14 & 1987 & Field clone \\
\hline 3 & Fu'an Dabaicha & 1985 & Landrace & 52 & Juhuachun & 1987 & OP \\
\hline 4 & Meizhan & 1985 & Landrace & 53 & Guihong 3 & 1994 & Field clone \\
\hline 5 & Zhenghe Dabaicha & 1985 & Landrace & 54 & Guihong 4 & 1994 & Field clone \\
\hline 6 & Maoxie & 1985 & Landrace & 55 & Yangshuling 783 & 1994 & Field clone \\
\hline 7 & Tieguanyin & 1985 & Landrace & 56 & Wannong 95 & 1994 & Field clone \\
\hline 8 & Huangdan & 1985 & Landrace & 57 & Xicha 5 & 1994 & Field clone \\
\hline 9 & Fujian Shuixian & 1985 & Landrace & 58 & Xicha 11 & 1994 & Field clone \\
\hline 10 & Benshan & 1985 & Landrace & 59 & Hanlv & 1994 & Field clone \\
\hline 11 & Daye Wulong & 1985 & Landrace & 60 & Longjing Changye & 1994 & Field clone \\
\hline 12 & Mengku Dayecha* & 1985 & Landrace & 61 & Zhenong 113 & 1994 & OP \\
\hline 13 & $\begin{array}{l}\text { Fengqing } \\
\text { Dayecha* }\end{array}$ & 1985 & Landrace & 62 & Qingfeng & 1994 & Field clone \\
\hline 14 & Menghai Dayecha* & 1985 & Landrace & 63 & Xingyang 10 & 1994 & Field clone \\
\hline 15 & $\begin{array}{c}\text { Lechang } \\
\text { Baimaicha* }\end{array}$ & 1985 & Landrace & 64 & Baxiancha & 1994 & Field clone \\
\hline 16 & Hainan Daye* & 1985 & Landrace & 65 & Qianmei 601 & 1994 & $\mathrm{HP}$ \\
\hline 17 & $\begin{array}{l}\text { Fenghuang } \\
\text { Shuixian* }\end{array}$ & 1985 & Landrace & 66 & Qianmei 701 & 1994 & HP \\
\hline 18 & Damianbai & 1985 & Landrace & 67 & Gaoyaqi & 1994 & Field clone \\
\hline 19 & $\begin{array}{l}\text { Shangmeizhou } \\
\text { Zhong }\end{array}$ & 1985 & Landrace & 68 & Zhuyeqi 12 & 1994 & Field clone \\
\hline 20 & Ningzhouzhong* & 1985 & Landrace & 69 & Baihaozao & 1994 & Field clone \\
\hline 21 & $\begin{array}{c}\text { Huangshang } \\
\text { Zhong* }\end{array}$ & 1985 & Landrace & 70 & Jiebohuang 13 & 1994 & Field clone \\
\hline 22 & Qimenzhong* & 1985 & Landrace & 71 & Shuyong 703 & 1994 & HP \\
\hline 23 & Jiukengzhong* & 1985 & Landrace & 72 & Shuyong 808 & 1994 & $\mathrm{HP}$ \\
\hline 24 & Yuntaishanzhong* & 1985 & Landrace & 73 & Shuyong 307 & 1994 & $\mathrm{HP}$ \\
\hline 25 & Meitan Taicha* & 1985 & Landrace & 74 & Shuyong 401 & 1994 & $\mathrm{HP}$ \\
\hline 26 & LingyunBaimaocha & 1985 & Landrace & 75 & Shuyong 3 & 1994 & $\mathrm{HP}$ \\
\hline
\end{tabular}


Review on Tea (Camellia Sinensis) Research Achievements, Challenges and Future Prospective Including Ethiopian Status

\begin{tabular}{|l|c|c|c|c|c|c|c|}
\hline & & & & & & \\
\hline 27 & Ziyangzhong* & 1985 & Landrace & 76 & Shuyong 906 & 1994 & HP \\
\hline 28 & Zaobaijie* & 1985 & Landrace & 77 & Yihongzao & 1998 & Field clone \\
\hline 29 & Yichang Dayecha* & 1985 & Landrace & 78 & Fuzao 2 & 2002 & Field clone \\
\hline 30 & Yixingzhong* & 1985 & Landrace & 79 & LingtouDancong & 2002 & Field clone \\
\hline 31 & Qianmei 419 & 1987 & OP & 80 & Xiuhong & 2002 & Field clone \\
\hline 32 & Qianmei 502 & 1987 & HP & 81 & Wulinghong & 2002 & Field clone \\
\hline 33 & Fuyun 6 & 1987 & OP & 82 & Yunda Danlv & 2002 & Field clone \\
\hline 34 & Fuyun 7 & 1987 & OP & 83 & Gancha 2 & 2002 & OP \\
\hline 35 & Fuyun 10 & 1987 & OP & 84 & Shuyong 808 & 2002 & HP \\
\hline 36 & Zhuyeqi & 1987 & Field clone & 85 & Shuchazao & 2002 & Field clone \\
\hline 37 & Longjing 43 & 1987 & Field clone & 86 & Wannong 111 & 2002 & Mutation \\
\hline 38 & Anhui 1 & 1987 & Field clone & 87 & Zaobaijian 5 & 2002 & Field clone \\
\hline 39 & Anhui 3 & 1987 & Field clone & 88 & Nanjiang 2 & 2002 & Field clone \\
\hline 40 & Anhui 7 & 1987 & Field clone & 89 & Zhenong 21 & 2002 & Field clone \\
\hline 41 & Yingshuang & 1987 & OP & 90 & E'cha 1 & 2002 & HP \\
\hline 42 & Cuifeng & 1987 & OP & 91 & Zhongcha 102 & 2002 & Field clone \\
\hline 43 & Jingfeng & 1987 & OP & 92 & Mingke 2 & 2002 & HP \\
\hline 44 & Biyun & 1987 & OP & 93 & Yuemingxiang & 2002 & Field clone \\
\hline 45 & Zhenong12 & 1987 & OP & 94 & Mingke 1 & 2002 & HP \\
\hline 46 & Shuyong 1 & 1987 & HP & 95 & Huangqi & 2002 & OP \\
\hline 47 & Yinghong 1 & 1987 & Field clone & 96 & Guilv 1 & 2003 & Field clone \\
\hline 48 & Shuyong 2 & 1987 & HP & 97 & Mingshan Baihao & 2005 & Field clone \\
\hline 49 & Ningzhou 2 & 1987 & Field clone & & & & \\
\hline
\end{tabular}

Source: China Tea Varieties Compilation Committee, 2001; MOA Bulletin No. 191, 2002

* Jat cultivars: (propagated by seeds), the others are clones Breeding methods:

Landrace: traditional cultivars, including jat cultivars and clones;

Field clone: individual selected clones from seedlings/jats;

OP: Clones selected from open-pollinated progenies;

HP: Clones selected from hand-pollinated progenies

\subsubsection{Breeding of the Tea Plant (Camellia sinensis) in India}

The indigenous Assam tea plant was discovered by Robert Bruce in 1823. The better cup quality produced by the Assam tea plant popularized it as an important planting material in the tea industries of the country. Considering the need for improved planting materials for the tea industry, Tocklai Experimental Station (TES) Tea Research Association, initiated a tea breeding programme in 1930, under which germplasms were collected based on trait specific phenotypic characteristics. The Tea Research Foundation, United Planters' Association of Southern India (UPASI), initiated a similar program in 1963 and collected germplasms were preserved in their gene bank. The technique of vegetative propagation standardized in 1955, provided scope for developing improved clonal cultivars as well as biclonal seed cultivars through hybridization. From the selected plants from old seed jats and progenies of biclonal hybrids, 153 locally adapted and 31 universal clones were developed for the tea industry. Marker development for draught resistance and blister blight disease is under progress using cDNA-AFLP techniques. The micropropagation technique has also been standardized for quick multiplication of these biotechnologically modified plantlets (Chen et al., 2012).

\subsubsection{Tea Improvement in Kenya}

Although tea was introduced into Kenya at the turn of the 20th century, concerted efforts at tea improvement could not take root until the early 1960s after the country gained self-rule from Britain. Owing to the heterogeneity of pioneer seedling populations that was accompanied by management constraints, early research efforts resulted in the development of whole single cuttings as propagation materials which, coupled with clonal selection, led to the release and commercialization of high yielding and quality clones. To date, the Tea Research Foundation has released a total of 50 high yielding and good quality tea clones for commercial utilization, not just in Kenya alone but also in the entire East African region. Furthermore, tea improvement activities integrating molecular markers 
Review on Tea (Camellia Sinensis) Research Achievements, Challenges and Future Prospective Including Ethiopian Status

and participatory clonal selection involving farmers and consumers are expected taste-track the development and adoption of novel varieties within a relatively short period (Samson et al., 2012).

\subsubsection{Breeding of tea plant (Camellia sinensis) in Sri Lanka}

Tea germplasm accessions conserved in field gene banks in Sri Lanka have not been adequately characterized in order to maximize its utilization in tea breeding programs. The unique morphological identity of each group was further confirmed using the available information related to their origin, ancestral relationships and locations of selections of the accessions. Moreover, it was able to identify key descriptors contributing to the phenotypic variation of the tea germplasm in Sri Lanka. This is the first extensive study reported so far on tea germplasm characterization using morphological descriptors, both locally and internationally. Furthermore, the exceptional morphological descriptors identified in this study would facilitate cultivar identification, which has become one of most demanding needs among tea growers after the introduction of new improved cultivars by the Tea Research Institute of Sri Lanka (Piyasundara et al., 2009).

\subsubsection{Breeding of tea plant (Camellia sinensis) in Vietnam}

Some new tea cultivars of high yield and good quality, suitable for production of green, black and Oolong teas such as LDP 1, LDP 2, PH 8, PH 9, have been developed. Tea breeding, however, needs to be further strengthened, and to this end the following activities need to be promoted: collecting and conservation of tea genetic resources, hybridization of native and exotic cultivars of C. sinensis and C. sinensis var. assamica, and use of mutation for speeding up the breeding cycle (Chen et al., 2012).

\subsection{Breeding strategy}

\subsubsection{Source of variation (gene pool)}

Tea production in the Southern Africa region is largely limited by climatic factors, particularly low and unevenly distributed rainfall and large fluctuation in temperatures, resulting in three distinct seasons. The thrust has therefore been to look for vegetatively propagated cultivars that are drought tolerant, have a low base temperature and are high yielding and that would thrive under these harsh conditions and make high quality teas in the main growing season. Initially the established seedling fields provided the gene pool from which elite mother bushes for VP (Vegetatively Propagated) cultivars were selected.This started in the mid 1950s and selection was based on drought tolerance and rate of recovery from prune. Some of the field selections were made at Swazi (now Nsuwadzi) research station in Malawi, e.g. SFS150 and SFS204 have become very popular cultivars in the region, each now covering over 100 hectares. In recognition of the limited natural variation for specific attributes expected of seedling tea population, a deliberate hybridization programme to create variable $\mathrm{F}$, progeny populations for specific attributes from which to select elite mother bushes for bulking up vegetatively, started in 1960 at the TRFCA (Ellis and Nyirenda, 1995).

\subsubsection{Selection of elite mother bushes}

Selection of elite mother bushes for quality attributes is based on fast fermentation, growth vigor, shoot size and tolerance to major pests and diseases. The chloroform test is very inexpensive (about USD 1/ genotype) and is used to classify plants as "slow", "medium" or "fast" fermenters (Sanderson, 1963). Using this test, the "slow" fermenters are eliminated from the selection programme in year 4. This occurs in the nursery plants, thus eliminating them from expensive field trials (Table 2). Selection of these attributes requires establishment of rapid and reliable selection criteria and methods (Apostolides et al., 2006).

Table2: Breeding and selection programme for new cultivars at the Tea Research Foundation in Central Africa (Malawi)

\begin{tabular}{|l|l|l|l|l|}
\hline Place & Year & Activity & $\begin{array}{l}\text { Number of } \\
\text { genotypes }\end{array}$ & $\begin{array}{l}\text { Number of plants } \\
\text { per genotype }\end{array}$ \\
\hline $\begin{array}{l}\text { Seed } \\
\text { Garden }\end{array}$ & 0 & Controlled crosses of flowers in seed garden & 5000 & 5000 \\
\hline Nursery & 1 & Germinate viable seeds in pots & 3750 & 3750 \\
\hline Nursery & 2,3 & $\begin{array}{l}\text { Select seedlings on the basis of plant vigor; } \\
\text { Take single cuttings for vegetative propagation }\end{array}$ & 2500 & 2500 \\
\hline
\end{tabular}


Review on Tea (Camellia Sinensis) Research Achievements, Challenges and Future Prospective Including Ethiopian Status

\begin{tabular}{|c|c|c|c|c|}
\hline Nursery & 4 & $\begin{array}{l}\text { Select seedlings on the basis of rooting ability and } \\
\text { nursery performance. Eliminate slow fermenters } \\
\text { (chloroform test) take } 30-50 \text { cuttings from } \\
\text { selected seedlings }\end{array}$ & 350 & 350 \\
\hline Field & 5 & $\begin{array}{l}\text { Plant cultivars in } 2 \times 8=16 \text { bush observation } \\
\text { plots in field. Mini-manufacture for organoleptic } \\
\text { assessment by expert tea taster }\end{array}$ & 150 & 2400 \\
\hline Field & $6,7,8$ & $\begin{array}{l}\text { Select cultivars on field performance and } \\
\text { organoleptic quality }\end{array}$ & 20 & 2400 \\
\hline Field & 9 & $\begin{array}{l}\text { Establish cultivars in replicated field trials of } 5 \times \\
6=30 \text { bushes per plot replicated five times, on } \\
\text { several research stations }\end{array}$ & 20 & 3000 per station \\
\hline Field & 10 & Early release of cultivars to estates & 5 & as required \\
\hline Field & $11,12,13,14$ & $\begin{array}{l}\text { Evaluation of cultivars on all traits for yield and } \\
\text { quality }\end{array}$ & 5 & 10,000 to 100,000 \\
\hline Industry & 15 & Possible release of $1-2$ new cultivars to industry & $0-3$ & as required \\
\hline
\end{tabular}

Source: Apostolides et al., 2006

\subsubsection{Collection and conservation}

The investigation of tea germplasms was initiated in China in the 1930s. However, large-scale and well-planned investigation and collection began in the 1980s. In 1990, the China National Germplasm Tea Repositories (CNGTR), including Hangzhou Tea Repository in the Tea Research Institute Chinese Academy of Agricultural Sciences (TRICAAS) and Menghai Tea Repository Branch in the TRI Yunnan Academy of Agricultural Sciences (TRIYAAS) were established as national level permanent ex-situ conservation repositories (Chen et al., 2004). About 2,665 germplasm accessions, including wild tea plants, landraces, improved clones, strains, genetic materials and others, from the tea growing provinces of China and several other countries around the world had been collected and preserved in the CNGTR by the end of 2003 (Chen et al., 2004). Meanwhile, repositories of different scale were established in the TRIs of other tea producing provinces mainly to conserve their local landraces (Liang et al., 2007).

\subsubsection{Early-stage appraisal technique for breeding}

Cup tea quality, yield and resistance are main tea breeding objectives. The desirable attributes for high crop yield and perhaps quality may not be likely to occur in more than one out of every 40,000 or more bushes (Wright, 1956; Hajra, 2001). It will take 22-25 years to successfully breed a new clone using traditional methods (Takeda, 2000). Thus, in order to shorten the breeding time and improve the breeding efficiency lots of research projects on early-stage appraisal technique for breeding have been carried out and achieved significantly. In early 1970s, research mainly focused on the simple relationships between the morphological characteristics and yield, cup tea quality and resistance. Since the late 1990s, DNA molecular markers have been used in early-stage appraisal (Chen et al., 2006c). The early stage appraisal of tea breeding is now advancing from morphological, physiological and chemical level to more precise DNA level (Liang et al., 2007).

\subsubsection{Genetic introgression to enhance germplasm innovation}

Germplasm innovation by distant hybridization has important role of broadening the genetic base. Ackerman (1973) attempted a large number of interspecific crosses involving 20 Camellia species. Tea could be easily crossed with 10 different species. In Japan, the distant hybridization of tea plant and 26 species in the genus Camellia were conducted. An interspecific hybrid between tea plant (C. sinensis) and flower camellia (C. japonica) and named Chatsubaki was obtained. It proved highly resistant to tea anthracnose, gray blight and cold damage in winter and furthermore had low caffeine content (Takeda et al., 1987). It has become one of the three promising parental materials for tea breeding in Japan. A clone TV 24 in Assam, India was produced by crossing between F1 hybrids (C. irrawadiensis X C.assamica) and TV1, an Assam-China hybrid (Bezbaruah, 1987).

\subsubsection{Hybridization breeding}

Hybridization is one of the main methods of obtaining genetic variation, and it is an important method of breeding new varieties. Totally 11 clones, corresponding to 73.3 percent of all clones bred using 
hybridization method, were bred from the controlled hybridization of Yunnan Dayecha (including Fengqing Dayecha) as female parent or male parent (data not shown). The percentage of clones bred using hybridization method increased significantly, from 9.1 percent for the first time (1987) to 29.1 percent for the second (1994) and 22.2 percent for the third (2002) time, respectively. Distant hybridization is a powerful method for broadening the genetic base of new varieties. Thanks to sterility or extremely weak fecundity, currently it could not be a routinely used method in the breeding of tea plant. Young embryo rescuing tissue culture strategy is now being developed to improve the success ratio of distant hybridization in the TRICAAS (Liang et al., 2007).

\subsubsection{Mutation breeding}

The combined effects of c-ray and chemical mutagens on biological damage to tea plant were systematically analyzed (Yang and Lin, 1992). The suitable dose rate and physicochemical combined mutation technique and criteria of main Chinese tea cultivars and a math model between radiation dose and effect of dose rate were proposed. One excellent new strain, which is very early sprouting in the spring, high cup tea quality, resistant to disease and suitable for fine green tea, has been selected from the offsprings of Longjing 43 cuttings under Co60c-ray radiation (Yang et al., 2003a). The TRI Hunan and Anhui Agricultural University had bred and registered a provincial and national clone using tea seedlings or seeds as radiation objects and Co60c-ray as radiation source in 1997 and 2002, respectively (Liang et al., 2007).

\subsubsection{Molecular marker assisted selection}

Presently, several molecular markers, such as RFLP, RAPD, CAPS, AFLP, ALPs, SSR, ISSR, have been developed and widely applied in the tea plant. Remarkable advances have been achieved for the analysis of genetic diversity and relationship, discrimination of varieties and cultivars, studies on molecular phylogenetics, detection of genetic stability and fidelity and, genome mapping (Chen et al., 2006c). It is possible to genetically manipulate and control the tea plant. This will bring tremendous effects to tea genetic improvement and breeding in the foreseeable future (Chen et al., 2006c; Liang et al., 2007).

\subsubsection{Micropropagation}

One of the difficulties in early breeding and extension stages of tea plant is reproduction. It is time consuming to propagate enough plantlets for strain comparative test, provincial and national adaptability tests. Moreover, it will take long time to propagate the new released clone for large scale extension. Where very few cuttings were available, it might take 8-10 years to multiply 4,000-5,000 plantlets using the conventional single node cutting method. However, only about 2 years might be sufficient to obtain the same quantity of plantlets using micropropagation methods (Cheng and $\mathrm{Li}$, 1998).

\subsubsection{Polyploidy and its application in tea breeding}

In tea, gigantism in various morphological characters has been found to be associated with tetraploids (Amma, 1974; Chaudhuri and Bezbaruah, 1985). Apart from increasing the biomass of crops (Allard, 1960), induced polyploids could be used as an additional source of genetic variation to improve the overall performance of existing diploids, or to enhance particular characters such as the shoot size trait (Wachira and Kiplangat, 1991), while retaining most of the characteristics of the diploid progenitor. In addition, they could also be used as a source of breeding material for the production of secondary polyploidy cultivars by crossing with diploids (Singh, 1980). Although the value of polyploids in overcoming barriers to inter-specific gene introgression has been recognized in plant species (Allard, 1960), this has not been fully exploited in perennial crops (Wachira and Ng'etich, 1999). On the other hand, non-conventional methods, such as polyploidy breeding, may induce more vigour and some degree of resistance to biotic and a biotic stresses in existing tea cultivars, without causing changes in the desired parts the genome (Simura and Inabe, 1952). There is a positive correlation between size of the leaf and the yield in tea (Satyanarayan and Sharma, 1982). Further, in asexually-propagated perennial crops such as tea, where the vegetative organs are economic value, polyploidy breeding can be used effectively in their genetic improvement (Gunasekara and Ranatunga, 2003). 
Review on Tea (Camellia Sinensis) Research Achievements, Challenges and Future Prospective Including Ethiopian Status

Table3: Identified polyploid clones, their chromosome number and ancestry

\begin{tabular}{|c|c|c|}
\hline Clone number & $\begin{array}{c}\text { Ploidy- } \\
\text { Chromosome No. }\end{array}$ & Orginal Seed Source \\
\hline *TRFK 311/287 & $4 n=60$ & TRFK 6/8 x TRFK 31/11 - hand-pollinated from TRIEA Uganda \\
\hline *TRFK 31/30 & $4 n=60$ & Seed from Ambangulu Estate, Tanzania \\
\hline *TRFK 52/1 & $3 n=45$ & "Between Seed from Kanywankoko Estate, Uganda \\
\hline$*$ TRFK 72/1 & $3 n=45$ & Open-Pollinated Seed from Mimosa Estate, Malawi \\
\hline *Dimbolil 3 & $3 n=45$ & Seedlings from James finlay (K) Ltd. Dimbolil Estate \\
\hline *TRFK 77/2 & $3 n=45$ & Open-Pollinated Seed from koiwa estate \\
\hline *TRFK 383/1 & $3 n=45$ & Open-pollinated BB35 X BB5, Koiwa Estate \\
\hline *TRFK 331/2 & $3 n=45$ & Seed from Chemosit Estate barie, Unilever tea \\
\hline *TRFK 378/1 & $3 n=45$ & Open-pollinated BB35 X BB7, Koiwa Estate \\
\hline *TRFK 412/1 & $3 n=45$ & Open-pollinated BB21 X BB5, Koiwa Estate \\
\hline *TRFK 371/1 & $3 n=45$ & Open-pollinated seed of AHP S15/10 from Chepgoiben Estate \\
\hline *TRFK 400/1 & $3 n=45$ & eed from Chepgoiben Estate barie \\
\hline *TRFK 389/1 & $3 n=45$ & Open-pollinated BB35 X BB152, Koiwa Estate \\
\hline *TRFK 392/1 & $3 n=45$ & Open-pollinated BB7 X BB35, Koiwa, Estate \\
\hline *TRFK 394/1 & $3 n=45$ & Open-pollinated BB2 X BB35, Koiwa, Estate \\
\hline *TRFK 395/1 & $3 n=45$ & Open-pollinated BB5 X BB35, Koiwa, Estate \\
\hline *TRFK 54/49 & $3 n=45$ & Seed from Ambangulu Estate, Tanzania \\
\hline TRFK 386/1 & $3 n=45$ & Seed from Sotik Tea Co \\
\hline TRFK 381/1 & $3 n=45$ & Seed from BB5 X BB2 \\
\hline TRFK 84/1 & $3 n=45$ & Mixed seed from Congo, Toro and Entebbe, Uganda \\
\hline TRFK $84 / 2$ & $3 n=45$ & Mixed seed from Congo, Toro and Entebbe,Uganda \\
\hline TRFK 85/1 & $3 n=45$ & Seed collected from clones from Kakonde Estate \\
\hline TRFK $382 / 2$ & $3 n=45$ & Seeds from BB5 X BB35 \\
\hline TRFK 382/1 & $3 n=45$ & Seeds from BB5 X BB35 \\
\hline TRFK 386/2 & $3 n=45$ & Seed from Sotik Tea Co \\
\hline TRFK 76/3 & $3 n=45$ & Seed from Ramjat, Lugeri Estate, Malawi \\
\hline TRFK 76/1 & $3 n=45$ & Seed from Ramjat, Lugeri Estate, Malawi \\
\hline TRFK 76/2 & $3 n=45$ & Seed from Ramjat, Lugeri Estate, Malawi \\
\hline TRFK 75/1 & $3 n=45$ & Commercial seed from Lugeri Estate, Malawi \\
\hline TRFK $31 / 36$ & $3 n=45$ & Seed from Ambangulu Estate, Tanzania \\
\hline TRFK $31 / 38$ & $3 n=45$ & Seed from Ambangulu Estate, Tanzania \\
\hline TRFK 31/39 & $3 n=45$ & Seed from Ambangulu Estate, Tanzania \\
\hline TRFK $31 / 40$ & $3 n=45$ & Seed from Ambangulu Estate, Tanzania \\
\hline TRFK 31/41 & $3 n=45$ & Seed from Ambangulu Estate, Tanzania \\
\hline TRFK $18 / 7$ & $3 n=45$ & Seed from Ambangulu Estate, Tanzania \\
\hline TRFK 18/27 & $3 n=45$ & Seed from Ambangulu Estate, Tanzania \\
\hline TRFK $18 / 26$ & $3 n=45$ & Seed from Ambangulu Estate, Tanzania \\
\hline TRFK 18/28 & $3 n=45$ & Seed from Ambangulu Estate, Tanzania \\
\hline TRFK 54/50 & $3 n=45$ & Seed from Ambangulu Estate, Tanzania \\
\hline TRFK 550/1 & $3 n=45$ & $\begin{array}{l}\text { Open-pollinated seed from polyclonal mixture, Timbilil Estate, } \\
\text { Kericho }\end{array}$ \\
\hline
\end{tabular}

Source: Wachira and Kiplangat (1991); Kamunya, 2010 NB: in tea, $n=x=15$.

\subsubsection{Genetic transformation in tea}

Foreign genes have been introduced in several woody crops including the rubber tree by using the Agrobacterium tumefaciens Ti plasmid (Horsch et al., 1985; Venkatachalam et al., 2006). Although the transgenic technology has immense potential for the genetic improvement of tea (Mondal et al., 2004; Lopez et al., 2004), the technique was hardly tried prior to 2000. This may have been caused by initial challenges in developing a viable protocol for gene transfer as well as efficient protocols for the in vitro regeneration of tea. Mondal et al. (2001) were able to optimize transformation conditions and production of transgenic tea via Agrobacterium tumefaciens.

\subsection{Tea industry in Ethiopia}

Tea is a new crop to Ethiopia which introduced in the early 19th century. The main government objectives to be self sufficient domestic consumption and save the foreign exchange spent for importing tea, to supply for export market by increasing the production and quality of tea through 
time and, to create employment opportunity for the citizens (MCTD, 2001). In Ethiopia, tea is produced by three estates (private tea plantation) viz. Wush-Wush and Gumero (Ethio Agri-Ceft P.L.C), and Chewaka (East Africa P.L.C) in south west of the country. Moreover, out-growers have produced and supplied green tea leaves to the three estates. Currently, the three estates hold a total area of 2660 ha under tea production and out-growers hold 437 ha for tea production. In the last five years (2011/12 to 2015/16), the three estates supplied a total of 4570.78 tons export and $34,126.1$ tons of tea for domestic market. Tea industry in Ethiopia has provided income and employment opportunities to 575 out-growers, 7139 temporary per annum and 1157 permanent workers at tea estates (EIAR, 2017).

Ethiopian high land tea is thus considered to be one of the best East African teas that could fetch premium prices in the world market (MCTD, 1991); the comfortable growth of tea in all coffee production areas is a good opportunity which permits the use of tea as an alternative crop in coffee diversification program in the country. Besides, it offers the coffee farmers the possibility to generate continuous income from the tea yield which is obtainable at every 10-15 days. The availability of plenty labor force in the country, as the production of tea requires an intensive human labor (EIAR, 2017).

\subsection{Challenges of tea research}

\subsubsection{Mini-manufacture}

This is limited by the age of the bushes when adequate leaf can be harvested and number of cultivars that can be mini-manufactured and tasted by expert tea tasters per season. There are also high electricity costs involved. Being a final confirmatory quality assessment, only short-listed potentially high quality selections should undergo this test. This can only be achieved when rapid, inexpensive screening methods are in place to eliminate poor quality genotypes in the early stages of selection (Maina et al., 2015).

\subsubsection{Time consuming protocols}

Most of the current selection methods can only start once the bushes have attained a particular stage. This is responsible for the long selection cycle making the programme expensive. The early methods of catechin analysis had to be abandoned because they were expensive and time consuming.

\subsubsection{Cost of assessment}

The current biochemical methods are expensive due to the need for special equipment and expertise. The limited funding to most research organizations makes it impossible to analyze all samples going through the breeding and selection process. For example, the fresh leaf catechins can be measured in a single two and a bud shoot, but cost about USD 101 per sample. The flavognost costs only about USD 8 per sample but can only be done after mini-manufacture that costs USD 50 per sample, plus $50 \mathrm{~g}$ fresh shoots costing another USD 10, for a total cost of USD 68. The catechin test is quite attractive due to the possibility of doing this test early (single bush, year 4) in the selection process (Maina $e t$ al., 2015).

\subsubsection{Climate change}

The impacts of climate change on tea production are the following: drying of the soils causing reduced water content in the tea, decreasing yields and negative impacts on quality; appearance of new pests and diseases; changes in the suitability of existing tea growing areas (In extreme cases, as temperatures become too high for tea cultivation, new suitable land areas need to be found; reduced biodiversity and ecosystem function as the result of habitat conversion, high-energy consumption (logged timber); sun scorch damage decreasing yields and lowering tea quality; reduced resilience of tea crops; uncertainty with application of fertilizers, high application of pesticides in some countries; increase in extreme weather events such as droughts, hail storms, floods, frosts, extreme rainfall and landslides (MCCTS, 2014; Maina et al., 2015).

\subsubsection{Pests and diseases}

The pests observed in farmers' fields were red spider mites, scales, thrips, aphids and crevice mites. Control measures suggested were cultural measures such as good nutrition. Over half of the farmers 
(54\%) indicated that Armillaria root rot is a problem in tea production. The control measure of this disease was reported to be uprooting the affected plants and venturing into different enterprises. Disease control measures suggested were; for Armillaria root rot; uprooting of the tea, for hypoxylon wood root; proper pruning, and for stem canker; use of chemicals. Other studies have also indicated these diseases affect tea (Otieno, 1997; Maina et al., 2015).

\subsubsection{Major constraints of Ethiopian tea industry}

The problem of low yield, which is mainly accounted to lack of technology recommendations suiting to Ethiopian condition, the use of adopted research technologies from other countries; particularly, that of Kenya's has been in use till presently. Tea Yield/ha in Ethiopia has been showing an increasing tendency from its early stage below $1300 \mathrm{~kg} / \mathrm{ha}$ is still very low as compared to other tea producing countries. As per the Food and Agricultural Report (FAO, 2001), in Assam tea, there was a world high production yield of $2,586 \mathrm{~kg} / \mathrm{ha}$ in Bolivia and as high as $6,700 \mathrm{Kg} / \mathrm{ha}$ has also been reported in Sri Lanka. Limitation of tea genetic resource base; thus less than 15 tea clones from introductions made so far. This has hindered attempts that could have been made to broaden and improve the existing narrow genetic base through different breeding approaches. The cultivation of tea in Ethiopia has been practiced by very few private large scales under limited locations and the most proportion (about $99.95 \%$ ) of potentially suitable tea lands is left unexploited till presently

\subsection{Future strategy or prospects of tea research}

\subsubsection{Main research emphases of tea genetics and breeding in the future}

Significant advances in tea breeding have been achieved and the breeding system has also progressed. The ultimate purpose of tea germplasms collection, conservation, appraisal and evaluation is to use their desirable genes. About $60 \%$ of the tea germplasms preserved in the CNGTR is jats (Chen et al., 2004). If the genetic background, superior characteristics and genes of the most important key hybridization parents are well studied, tea breeding in China will have a breakthrough and the change from germplasms predominance to new clone predominance will be realized with the assistance of new breeding techniques and methods (Chen et al., 2004). Our newly developed medium density cDNA microarray of tea plant may provide a possible tool for high-throughput germplasms appraisal on the gene level (Zhao et al., 2006; Liang et al., 2007).

\subsubsection{Deepening the functional genome research to reveal special gene resources}

The isolation of functional genes from tea plant was initiated in 1992 and advanced slowly owing to the distinctness of tea plant from other taxa (Zhao et al., 2003). Totally 1,684 ESTs and the partial sequences of more than 300 functional genes, including some important secondary metabolism and stress/defense related genes have been generated (Chen et al.,2005c). Consequently, it is necessary to increase input and promptly deepen the functional genome research, in order to reveal specific genes of tea plant, to better understand the mechanism of genetic variation on the whole genome level for tea breeding (Liang et al., 2007).

\subsubsection{Enhancing basic genetic research for breeding}

The genetic characteristics of the tea plant are still poorly understood and it causes significant negative effects to tea breeding. Thereby, the techniques and approaches of modern molecular biology should be employed to enhance the genetic understanding of important agronomic traits, quality, metabolism and resistance. It will help to guide tea breeding, to enhance the precision and to improve the efficiency (Liang et al., 2007).

\subsubsection{Conducting distant hybridization to enhance germplasm innovation}

Germplasm innovation has the function of pre-breeding and has the important role of broadening the genetic base and improving the effectiveness of breeding. Along with the discovery of excellent germplasms, innovation should be enhanced in order to provide breakthrough germplasms for breeding. The method of innovation is diverse; a main important one is hybridization, including distant hybridization. In Japan, the distant hybridizations of tea plant and 26 species in the genus Camellia were conducted. An interspecific hybrid between tea plant (C. sinensis) and flower camellia (C. japonica) named Chatsubaki was obtained. It proved highly resistant to tea anthracnose, gray blight and cold damage in winter and, furthermore had low caffeine content (Takeda et al., 1987). 
Review on Tea (Camellia Sinensis) Research Achievements, Challenges and Future Prospective Including Ethiopian Status

\subsubsection{Improving gene transformation technique to use exogenous genes}

Using gene engineering techniques, desirable exogenous genes from other organisms are able to be introduced into tea plants, new varieties with new characteristics are able to be created and desirable traits of two clones are able to be combined together. There is a successful case of transgenic tea plant in India (Mondal et al., 2001). Meanwhile, there are several research projects in China, using both particle bombardment and Agrobacterium mediated or combined transformation methods (Luo and Liang, 2000; Zhao et al., 2001; Wu et al., 2003, 2005). Furthermore, RNA mediated posttranscriptional gene silencing technique might be used to make low or nil caffeine tea clones. The key genes of caffeine synthesis pathway such as caffeine synthase (Kato et al., 2000) and S-adenosyl methionine synthase (Feng and Liang, 2001) genes could be sequence specifically degraded by double stranded RNA (dsRNA) using antisense messenger RNA technique. The bottleneck is that the transformation receptor system is still problematic. So, great attentions should be paid in the gene transformation technique to improve it, and make transgene an effective routine approach for germplasm innovation (Liang et al., 2007).

\subsubsection{Molecular marker assisted technique to effectively conduct early-stage appraisal}

There are many early-stage appraisal approaches available in tea breeding which include morphological, physiological, chemical and molecular methods. Informative DNA markers are used to construct high density genetic linkage map, to locate the quantitative trait locus (QTL) of important agronomic traits, quality and resistance, showing bright prospects in tea breeding via marker assisted selection. The first linkage map for tea plant was constructed with RAPD markers by Tanaka (1996), and the markers related with theanine content, date of bud sprouting, resistance to anthracnose and tolerance to cold were detected (Tanaka,1996). Another linkage map from the female parent, SFS150, was established with RAPD and AFLP markers (Hackett et al., 2000).

\section{SUMMARY AND CONCLUSION}

Tea [Camellia sinensis (L.) O. Kuntze] is one of the most popular and lowest cost beverages in the world, and consumed by a wide range of age groups in all levels of society with more than three billion cups daily worldwide. The TRI holds the second largest tea preservation resource in the world and currently conserves 3,013 different tea germplasm resources, encompassing the most genetic diversity of any tea resource in the world. In total, researchers at TRI have contributed 225 scientific and technological advances to the field 106 of these achievements have been recognized with awards, including eight national and 39 ministerial prizes. The TRFCA has an active plant breeding and selection programme aimed at solving tea production problems such as drought, extreme temperatures, pests and diseases, low yield and low quality, under local growing conditions in order to increase productivity and maximize total value and income from the crop. Early sprouting in the spring, high cup quality, high yield, high resistant to biotic and a biotic stresses and, some special characteristics (such as low caffeine, high Catechins, etc.) are the main tea breeding objectives in the present stage and foreseeable future. Many improved, high-yielding tea cultivars possess one or a few undesirable traits such as susceptibility to pests and diseases, which preclude their extensive use in commercial planting. The problem of low yield, which is mainly, accounted to lack of technology recommendations that suiting to Ethiopian condition.

In conclusion to develop promising cultivars, breeding strategies, which combine high yield, good cup quality and resistance to biotic and a biotic stresses, are required to obtain high productivity and to reduce the cost of production. The challenges like mini-manufacture, cost assessment, climate change, time consuming protocols, pest and diseases, labour, soil erosion, machine picking were affected mainly tea industry including Ethiopian. In the future the tea research must emphasize on tea genetics and breeding, deepening the functional genome research to reveal special gene resources, enhancing the basic genetic research for breeding, conducting distant hybridization to enhance germplasm innovation, improving gene transformation technique to use exogenous genes, Perfecting molecular marker assisted technique to effectively conduct early-stage appraisal and similar procedures should be integrated in the future tea research in order to cope up with the currently existing environmental phenomena.

\section{REFERENCES}

[1] Ackerman WL (1973). Species compatibility relationships within the genus Camellia .J.Hered, 64:356-358 
Review on Tea (Camellia Sinensis) Research Achievements, Challenges and Future Prospective Including Ethiopian Status

[2] Ahmed N, Singh ID (1993). A technique for rapid identification of ploidy level in tea. Two and a Bud 40, 31-33.

[3] Allard RW (1960). Principles of Plant Breeding. John Wiley and Sons Inc., New York; p. 411-422.

[4] Amma S (1974). Characteristics of tetraploid tea induced from gamma irradiated Yabukita variety. Study of Tea 46, 1-6.

[5] Apostolides Z, Nyirenda HE, Mphangwe NIK (2006). Review of tea (Camellia sinensis) breeding and selection in Southern Africa; Plant breeding and selection in Southern Africa; IJTS 5(1)2006

[6] Basu MA, Bera B, Rajan A (2010). Tea Statistics: Global Scenario. Inc. J. Tea Sci. 8 (1): 121-124

[7] Bezbaruah HP (1976). Aneuploidy in tea. Nucleus 19,167-169.

[8] Bezbaruah HP, 1987. Use of interspecific hybrids in tea breeding; Two Bud, 34: 1-4

[9] Chaudhuri TC, Bezbaruah HP (1985). Morphology and anatomy of aneuploid and polyploid tea (Camellia sinensis (L.) O. Kuntze). J. Plantation Crops 13, 22-30.

[10] Chaudhuri TC (1979). Studies on the morphology and cytology of the progenies of triploid tea (C. sinensis L.). Ph D thesis, Assam Agriculture University, Jorhat, Tocklai Experimental Station; 176 pp.

[11] Chen L, Yao MZ, Zhao LP, Wang XC (2006c). Recent research progresses on molecular biology of tea plant (Camellia sinensis). In: da Silva JT (ed) Floriculture, ornamental and plant biotechnology, advances and topic issues, vol 4. Global Science Books, London, pp 425-436

[12] Chen L, Zhao LP, Gao QK (2005c). Generation and analysis of expressed sequence tags from the tender shoots cDNA library of tea plant (Camellia sinensis). Plant Sci 168(2):359-363

[13] Cheng H, Li SF (1998). Biotechnology in 21st century and tea industry. In: China Tea-men Association (ed.) Proceedings of Chinese Tea Industry in the $21^{\text {st }}$ Century. Hangzhou, China, pp 90-104

[14] China Tea Varieties Compilation Committee, 2001. China Tea Varieties. Shanghai Scientific and Technical Publishers, Shanghai

[15] EIAR , 2017. Ethiopian Institute of Agricultural Research, National Tea Commodity Research Strategy (2016 - 2030), January 2017

[16] Ellis R, Nyirenda HE (1995). A successful plant improvement programme on tea (Camellia sinensis). Expl. Agric. 31:307-323.

[17] Feng YF, Liang YR (2001). Cloning and sequencing of S-adenosylmethionine synthase gene in tea plant. J Tea Sci 21:21-25

[18] Gunasekara M T K and Ranatunga MAB (2003). Polyploidy in tea (Camellia sinensis 1.) and its application in tea breeding: A Review Plant Breeding Division, Tea Research Institute of Sri Lanka, Talawakelle, Sri Lanka; 68(2), 14-26

[19] GWWTF (2007). Gumero and Wush Wush Tea Farm; Addis Ababa Ethiopia

[20] Hackett CA, Wachira FN, Paul S, Powell W, Robbie W (2000). Construction of a genetic linkage map for Camellia sinensis (tea). Heredity 85(4):346-355.

[21] Hajra NG (2001). Advances in selection and breeding of tea a review. J Plantation Crops 29(3):1-17

[22] Hick A (2009). Current status and future development of global tea production and tea product. Assumpt. Univ. J. Technol., 12: 251-264

[23] Hilton PJ, Ellis RT (1972). Estimation of the market value of Central African teas by theaflavin analysis. J Sci Food Agric. 23: 227-232.

[24] Horsch RB, Fry JE, Hoffmann NL, Eichholz D, Rogers SG, Fraley RT (1985). A simple and general method for transferring genes into plants. Science 227:1229-1231

[25] Huang FP, Liang YR, Lu JL, Chen RB, Mamati G (2004). Evaluation of genetic diversity in Oolong tea germplasms by AFLP fingerprinting. J Tea Sci 24:183-189

[26] Huang JA, Li JX, Huang YH, Luo JW, Gong ZH, Liu ZH (2005). Construction of AFLP molecular markers linkage map in tea plant. J Tea Sci 25:7-15

[27] Kamunya SM., Francis N,Wachira, Ram S. Pathak, Richard C, Muoki , Ram K. Sharma (2012). Tea Improvement in Kenya; Global Tea Breeding@ Zhejiang University Press, Hangzhou and Springer-Verlag Berlin Heidelberg

[28] Kamunya SM (2010). Genetic Parameters and Quantitative Trait Loci Mapping in Tea, Camellia sinensis (L.) O. Kuntze;A Thesis Submitted to the Graduate School in Fulfillment of the Requirements for the Degree of Doctor of Philosophy in Agronomy (Plant Breeding) of Egerton University.

[29] Kato M, Mizuno K, Crozier A, Fujimura T, Ashihara A (2000). Caffeine synthase gene from tea leaves. Nature 406:956-957 
Review on Tea (Camellia Sinensis) Research Achievements, Challenges and Future Prospective Including Ethiopian Status

[30] Liang C, Zhi-Xiu Z, Ya-Jun Y (2007). Genetic improvement and breeding of tea plant (Camellia sinensis) in China: from individual selection to hybridization and molecular breeding, Euphytica 154:239-248

[31] Liang YR, Tanaka J, Takeda Y (2000). Study on diversity of tea germplasm by RAPD marker. J Zhejiang Forest College 17:215-218

[32] Lopez SJ, Kumar RR, Pius PK, Muraleedharan N (2004). Agrobacterium tumefaciens-mediated genetic transformation in tea (Camellia sinensis (L.) O. Kuntze). Plant Molecular Biology Reporter 22:201a-201j

[33] Luo YY, Liang YR (2000). Study on the construction of Bt gene expression vector and its transformation in tea plant J Tea Sci 20(2):141-147 Maina FN, Mathenge PW, Mwathe ZM, Mathenge MM, 2015. Chanllenges facing the tea sector in Nyeri Country; Proceedings of the First International Conference on Tea Science and development Karatina University, School of Agriculture and Biotechnology.

[34] MCCTS, 2014. Mitigating Climate Change in Tea Sector, International Trade Centre 2014

[35] Ming-Zhe Y, Liang C (2012). Tea Germplasm and Breeding in China ; Global Tea Breeding ;Tea Research Institute of the Chinese Academy of Agricultural Sciences; National Center for Tea Improvement, 9 South Meiling Road, Hangzhou, Zhejiang 310008, China

[36] Ministry of Agriculture of the People's Republic of China, 2002; Bulletin No. 191

[37] Ministry of Coffee and Tea Development, 1991. Ministry of Agriculture and Rural Development. Addis Ababa, Ethiopia

[38] Ministry of Coffee and Tea Development, 2001. Ministry of Agriculture and Rural Development. Addis Ababa, Ethiopia

[39] Mondal T, Bhattacharya A, Ahuja P, Chand P (2001).Transgenic tea [Camellia sinensis (L.) O. Kuntze cv. Kangral Jat] plants obtained by Agrobacterium-mediated transformation of somatic embryos. Plant Cell Rep 20:712-720

[40] Mondal TK, Bhattacharya A, Laxmikumaran M, Ahuja PS (2004). Recent advances of tea (Camellia sinensis) biotechnology. Plant Cell, Tissue and Organ Culture 76: 195-254.

[41] Nainanayake AD (2004). Impact of drought on coconut (Cocos nucifera L.): Screening germplasm for evaluating fermenting properties of clones. Tea Quarterly 34:193-196.

[42] Nga'ng'a SI (2014). Support Tea Research. www.karatinauniversity.ac.ke Accessed 27/8/2014.

[43] Ng'etich WK, Wachira FN (1992). Use o f non-destructive method of leaf area estimation in triploid and diploid tea plant (Camellia sinensis). Tea 13,11-17.

[44] Otieno W (1997). Epidemiology and management of hypoxylon wood rot of tea. Tea. 18: 175-83.

[45] Owuor P, Obanda M (1995). Clonal variation in the individual theaflavin levels and their impact on astringency and sensory evaluations. Food Chemistry 54: 273-277.

[46] Piyasundara JHN, Gunasekare MTK, Wickramasinghe IP (2009). Characterization of Tea (Camellia sinensis L.) Germplasm in Sri Lanka using Morphological Descriptors; L. J, Tea Sci. 74(1), 31 -39

[47] Ranatunga MAB and Gunasekare MTK (2002). Identification of ploidy markers in tea (Camellia sinensis L.). Proc. Annual Sessions Sri Lanka Assoc. for the Advancement of Science, p. 38.

[48] Rashid A, Chowdhury M, Badrul Alam AM (1985).Studies on the progenies of a cross between diploid and tetraploid tea. Sri Lanka J. Tea Sci. 54, 54 - 61.

[49] Sanderson GW (1963). The chloroform test. A study of its suitability as a means of rapidly

[50] Sarmah PC and Bezbaruah HP (1984).Triploid breeding in tea. Two and a Bud 31,55-59

[51] Satyanarayan N and Sharma VS (1982). Biometric basis for yield prediction in tea clonal selection. Proc. 4 1 h Symp. on Plantation Crops, p. 237-243.

[52] Satyanarayana N and Sharma VS (1993). UPASI biclonal seed stocks, Proc. Sixth Joint Area Scientific Symposium (JASS VI), In UPASI Tea Res. Inst. Bull., 46:144-54.

[53] Sean S , Tianna H ,Wayne P (2013). The Chinese academic of Agricultural Sciences ;Enhancing the Role of Agricultural Science and Technology visit aaas.org/plusyou/fellows

[54] Sharma VS and Ranganathan V (1986). Present status and future needs of tea research. In Plantation Crops. Oxford and I B H Publishing Co., New Delhi; pp 37-50.

[55] Sharma VS and Ranganathan V (1985).The world of tea today. Outlook on Agriculture 14,35-40.

[56] Simura T, Inabe T (1952). Studies on polyploidy of the tea plant. Tokai-kinki National Agricultural Experimental Station, Research Progress Report 1,1-14.

[57] Singh ID (1980). Non-conventional approaches in the breeding of tea in North East India. Two and a Bud $27,3-6$ 
[58] Suresh CD , Sudripta D , Mridul H (2012). Breeding of the Tea Plant (Camellia sinensis) in India, Global Tea Breeding@ Zhejiang University Press, Hangzhou and Springer-Verlag Berlin Heidelberg;Tocklai Experimental Station, Tea Research Association, Jorhat 785008, Assam, India

[59] Takeda Y (2000). History and development in Japanese tea breeding. In: Park YG, Shin DI (ed) Tea Culture, Tea Food Industry and Tea Breeding in Korea, China and Japan. The Korea Tea Society, Korea, pp 139-158.

[60] Takeda Y, Yanse Y, Amma S (1987). Breeding of interspecific hybrids between Camellia sinensis(L.) O. Kuntze and C. japonica L. and their characteristics. Inst. Veg. Orna. Tea(B),1:11-22

[61] Tanaka J (1996). RAPD linkage map of tea plant and the possibility of application in tea genetics and breeding. Tea Res J 84(S):44-45.

[62] Venkatachalam P, Jayashree R, Rekha K , Sushmakumari, Sobha S, Jayasree PK, Kala RG, Thulaseedharan A (2006). Rubber Tree (Hevea brasiliensis Muell.Arg). Methods in Molecular Biology 344:153-164.

[63] Wachira FN, Kiplangat J K ,1991. Newly identified Kenyan polyploid tea strains. Tea 12, 10-13.

[64] Wachira FN, Muoki RC (1997). Nucleolar and nucleolus organizer region activity in tea as visualized by silver staining. African Crop Sci. Journal 5,253-258.

[65] Wachira FN, Ng'etich WK (1999).Dry matter production and partition in diploid, triploid and tetraploid tea. J. Horticultural Sci. and Biotechnology 74,507-512.

[66] Wachira FN (1994).Triploidy in tea (C. sinensis): effects of yield and yield attributes. J. Horde. Sci. 69, 53 -60 .

[67] Weru J (2014). Bid to End Tea, Coffee Farmers Woes. 19 April 2010. Web. 27 Feb 2011. http://www. standardmedia.co.ke

[68] Wright W (1956). Commercial selection and breeding of tea in India. World Crop 8:263-268

[69] Wu S, Liang YR, Lu JL, Kim H, Wu Y (2003). Optimization of Agrobacterium mediated and particle bombardment mediated transformation systems in tea plant (Camellia sinensis). J Tea Sci 23(1):6-10

[70] Wu S, Liang YR, Lu JL, Li HY (2005). Combination of particle bombardment mediated and Agrobacterium mediated transformation methods in tea plant. J Tea Sci 25(4):255-264

[71] Yang YH, Lin SQ (1992). The study on artificial mutation technique of tea plant. In: Tea Research Institute CAAS (ed) Tea Science Research Proceeding. Shanghai Scientific and Technical Publishers, Shanghai, pp 45-54

[72] Yang YJ, Yang SJ, Yang YH, Zeng JM (2003a). The breeding of an early sprouting and high quality new clone suitable for fine green tea. J China Tea 25(2):13-15

[73] Zhao D, Liu ZS, Lu JL, Tu YY, Xi B (2001). Study on Agrobacterium tumefaciens-mediated transformation of tea plant. J Tea Sci 21(2):108-111

[74] Zhao LP, Chen L, Gao QK ( 2003). The advancement of gene cloning and genetic transformation and the prospect of EST in functional genomics research of tea plant (Camellia sinensis). In: China Tea Science Society (ed.) Proceedings of third tea industry symposium across the Taiwan Straits. Changsha, China, pp 292-300

[75] Zhao LP, Gao QK, Chen L, Wang XC, Yao MZ (2006). Development and preliminary application of cDNA microarray of tea plant (Camellia sinensis). J Tea Sci 26(3):166-170

Citation: M. Zakir, "Review on Tea (Camellia sinensis) Research Achievements, Challenges and Future Prospective Including Ethiopian Status ", International Journal of Forestry and Horticulture, vol. 3, no. 4, p. 27-39, 2017. http://dx.doi.org/10.20431/2454-9487.0304005

Copyright: (C) 2017 Authors. This is an open-access article distributed under the terms of the Creative Commons Attribution License, which permits unrestricted use, distribution, and reproduction in any medium, provided the original author and source are credited. 